\title{
The Effect of Spatial Intelligence-based Metalinguistic Written Corrective Feedback on EFL Learners' Development in Writing
}

\author{
Mehdi Solhi Andarab ${ }^{1, *}$ \\ ${ }^{1}$ School of Education, Istanbul Medipol University, Istanbul, Turkey \\ *Correspondence: School of Education, Istanbul Medipol University, Istanbul, Turkey. Tel: 90-216-681-5100. E-mail: \\ solhi.mehdi@gmail.com
}

Received: January 6, 2019

Accepted: February 9, 2018 Online Published: February 22, 2019

doi:10.5430/jct.v8n1p40

URL: https://doi.org/10.5430/jct.v8n1p40

\begin{abstract}
Correcting and providing feedback to the written work of the learners has always been one of the hotly-debated issues over the last decades. While a group of scholars argue in favor of the effectiveness of the written corrective (CF) feedback, others question the utility and usefulness of the CF on writing of the learners. Even there seem to be fewer consensuses on the typology of the CF. Metalinguistic written CF (e.g., brief grammatical descriptions and error codes) is a type of written feedback, through which teacher gives metalinguistic clue to the nature of the errors (Ellis, 2009). In this study, a different type of metalinguistic feedback, conceptualized as spatial intelligence-based (SIB) metalinguistic written CF, was used while providing feedback to the learner's work, using the colorful stationery to write, highlight, locate, or underline the linguistic errors of the learners while giving feedback. In order to investigate the effectiveness of SIB metalinguistic written CF on English as a foreign language (EFL) learners' development in writing, 47 intermediate learners were randomly assigned into two groups. The learners in the first group received SIB metalinguistic written CF for their errors in writing, while the ones in the second group only obtained metalinguistic written CF for their errors. An independent samples t-test applied on the scores achieved from a posttest showed a significant difference in scores of the first group and that of the experimental group. Results indicated that the accuracy (mechanics) and style of the writing of the first group of students who received SIB correction for their linguistic errors exceled that of the second group students whose received written correction was only metalinguistic. However, there was no significant difference between the groups in the content, and organization of their writing.
\end{abstract}

Keywords: corrective feedback, spatial intelligence, spatial intelligence-based metalinguistic corrective feedback

\section{Introduction}

In Longman Dictionary of Language Teaching and Applied Linguistics, the term feedback in teaching is defined as "comments or other information that learners receive concerning their success on learning tasks or tests, either from the teacher or other persons". The common types of teacher feedback encompass written comments, individual conferences, and recorded oral feedback (Weigle, 2014). As writing skill is concerned, written corrective feedback (CF) is a type of input (feedback) from a reader (teacher) to a writer (student) with an effort to provide information to the writer for revision. Simply put, it includes the comments, explanations, suggestions, and questions that a reader provides a writer. Through given feedback, the writer identifies the areas that are misleading or confusing to the reader because of providing insufficient information, irrational organization, inappropriate choice of word or tense, or inadequacy in developing ideas (Keh, 1990).

\subsection{Literature Review}

Despite the significance of providing feedback to the written work of the learners, there seem to be fewer consensuses on the effectiveness of error correction in writing (Ferris, 2006). Hyland and Hyland (2006) similarly emphasize that despite the fact that supplying feedback to learner's writing possesses a pivotal role in writing programs across the world, uncertainty on its constructive role exists in literature review. According to the teachers' perception in their observation, the potential of $\mathrm{CF}$ is not fully utilized. This uncertainty, according to Guenette (2007), can stem from the poor and unsystematic design of the studies assessing the constructive effect of the 
different types of $\mathrm{CF}$ in writing, resulting into the lack of control for extraneous variables that are likely to impact the effectiveness of the CF in the subsequent writing of the learners. Hence, how feedback providers (teachers) correct the learners' writing is a hot topic that has drummed up considerable interest from both researchers and teachers (Ellis, 2009).

Despite the tendency of language teacher to focus on sentence-level accuracy, commenting primarily on content before on linguistic issues is emphasized by a plethora of scholars (e.g., Ferris \& Hedgcock, 2004; Williams, 2005). It is only after content first step that the details can be thoroughly considered. As that is not literally possible to deal with every issue, prioritizing the errors carried a significant importance. Therefore, the errors that are more likely to hamper comprehension, the stigmatized ones, and the issues that are the current focus of instruction are to be taken into consideration in the process of giving feedback to writing (Weigle, 2014).

Ellis (2009) categorizes the typology of written CF on the correction of the learner's linguistic errors: direct, indirect, metalinguistic, focused/unfocused, electronic feedback, and reformulation. In direct CF, the teacher supplies the students with the correct form. This type of feedback can be conducted by "crossing out an unnecessary word, phrase, or morpheme, inserting a missing word or morpheme, and writing the correct form above or near to the erroneous form" (p. 3). Minimal mental processing on the part of the students is a disadvantage of this type of feedback, while it is believed to be useful while working with students possessing low-level of proficiency, as they may not be proficient enough to self-correct the mistakes based on the feedback given (Ferris and Roberts, 2001, as stated in Ellis, 2009). In the case of indirect CF, the error is indirectly indicated to the students without correcting it. "(U)underlining the errors or using cursors to show omissions in the student's text or... placing a cross in the margin next to the line containing the error" are some ways to indirectly supply CF to the linguistic errors of the student (p. 4).

Metalinguistic CF that is the focus of this study, according to Ellis (2009), can be given by either providing explicit comment (metalinguistic explanations) on the nature of the error, or by using error codes for each type of error. The latter type of metalinguistic CF (i.e., the use of error codes or abbreviated labels for different kinds of errors) is the more common type of metalinguistic CF to writing. Although the former, as Weigle (2014, p. 232) states, "can reinforce the strengths of a paper or indicate areas where improvement is needed", it can by far be more time consuming and are more likely to lead to some kinds of misunderstandings. It also requires the teacher to have enough metalinguistic knowledge to provide detailed and adequate explanations for different types of errors. The utility of incorporating coherent and succinct metalinguistic feedback have been confirmed in a number of studies investigating the effectiveness of CF (Bitchener \& Knoch, 2010; Heift, 2010). In focused CF, only some types of errors (e.g., articles, propositions, or tenses) are taken into account, while in unfocused CF learner is exposed to the correction of a large variety of errors. In fact, students receiving unfocused CF are less likely to be able to focus on each error than focused $\mathrm{CF}$ in which the student can reflect on multiple corrections of a single or a few errors (Ellis, 2009). In electronic feedback, search engines such as Google is used to render assistance to the students in their writing. In reformulation, the last type of $\mathrm{CF}$, a native-speaker of a language is required to rewrite (reformulate) the student's work, provided that $\mathrm{s} / \mathrm{he}$ preserves the writer's ideas as much as possible while restating them in an authentic and natural language.

With its main focus upon recognizing the color and form, the integration of spatial intelligence, one of Gardner's (1993) multiple intelligences, in the process of learning a language in particular has always possessed an enormous significance. Providing learners with visual mapping activities and encouraging students to create charts and bulletin boards, and establishing classroom atmosphere in which the learners can draw pictures are some of the significant features of spatial intelligence. The utilization of photography, visual materials, mind mapping, and visualization in general are suggested to activate the spatial intelligence profile of the learners (Armstrong, 2000; 2003, and Christison, 1996). As far as giving feedback is concerned, integrating spatial intelligence to provide feedback to the written work of the learners can be categorized as a different type of metalinguistic $\mathrm{CF}$, in which a variety of colors are exploited while providing $\mathrm{CF}$ to the writing of the learners. This type of CF can be conceptualized as spatial intelligence-based (SIB) metalinguistic written CF through which linguistic errors of the learners can be underlined, highlighted or indicated, using the colorful supplies to activate their observation skills and imagination, and capture their attention when providing feedback. Otto (2013) indicates that the utilization of colors and visualization can boost learners' perception of the writing process and improve their writing skill by simplifying the writing process. Moody (2012) similarly asserts that integration of visual materials can lead learning into a different transformative process, as the learners are more likely to be involved in manipulative manner, and encouraged to ask and discuss questions. 
As Vyatkina (2011) believes, detailed investigations indicating how teachers and language program directors actually deal with written corrective feedback has remained scarce. Guenette (2007) similarly indicates studies systematically scrutinizing corrective feedback have been quite insufficient. Despite the plethora number of studies conducted to investigate the effectiveness of metalinguistic CF on the written work of the learners (e.g., Ferris \& Hedgcock, 2004; Lalande, 1982; Lee, 1997; Robb et al., 1986; Truscott, 1996), seemingly no studies have been carried out to assess the effect of SIB metalinguistic written CF on EFL learners' development in writing. The purpose of this study was to explore this gap, investigating the effect of SIB metalinguistic written CF on the learners' writing, in an attempt to investigate whether receiving this type of feedback for the written work could be regarded as a predictor of the learners' development in writing. To this end, the following research question was taken under investigation in this study:

Q: What is the effect of SIB metalinguistic written CF on EFL students' development in writing?

\section{Methods}

\subsection{Participants}

The participants in this study were the learners studying at the preparatory school of a private university in Turkey. At first, 47 intermediate EFL learners, aged 18-23, were randomly assigned into two groups. Their level of proficiency (i.e., intermediate) in English had already been assessed through the placement and proficiency exams of the university respectively.

\subsection{Procedure}

The purpose of the study was to examine the learners' improvement in new pieces of writing over a three-month period of time. The both groups received metalinguistic written CF (e.g., brief grammatical descriptions and error codes) for their linguistic error in writing. However, the treatment in the first group was based on SIB metalinguistic written CF. The learners in the two groups were expected to write different types of essays on different topics, following the main phases of the writing process: pre-writing, drafting, responding, revising, editing, and evaluating. In the phases that require feedback (i.e., drafting and evaluating), the teacher gave the abovementioned CF to their writing. At the drafting stage, the learners were focused on the fluency of writing and were not preoccupied with grammatical accuracy or the neatness of the draft. Responding intervenes between drafting and revising, and at this stage the teacher's quick initial reaction to students' draft was supplied. After receiving the feedback, at the revising phase and editing respectively, the learners were supposed to make the required changes based on the feedback received. At the final phase, their revised essays were evaluated and put in the portfolio to keep track of the learners' longitudinal progress. The feedback for both groups lasted for about three months, three days a week. Each learner wrote approximately five pieces of writing in this period of time.

\subsection{Data gathering}

At first, a pre-test, in which the participants were required to write a couple of short essays, was administered in order to assure they have somehow similar former knowledge on writing. The time allotted to the learners to write was 90 minutes. The categories in the rubric used for assessing the written knowledge of the participants include content/development, organization, style, and mechanics. The pre-test served the purpose of selecting a homogeneous group of students for the treatment. No significant difference was seen between the obtained score of the first group and that of the experimental group. Finally, to arrive at the purpose of the study, a post-test, in which the learners were expected to write three different types of essays (i.e., classification, problem-solving, and cause/effect), was administered. In order to observe the numerical scores resulting from the post-test followed by the SIB metalinguistic CF for the first and only metalinguistic CF for the second groups, an independent samples t-test was applied to examine the possible significant difference between them, and to observe the intended improvement. The rubric used to assess the writings of the students comprised of four categories: content, organization, style, and mechanics. The grading was 25 for each category. In content, clarity and appropriateness of the stated main and supporting ideas in the paragraphs were the focus of attention. In organization, the structure and organization of the different sections of the essay (i.e., introduction, body, and conclusion) were taken into consideration. In style, how smooth, coherent, and consistent the writing was, and the strength and expressiveness of the sentences were thoroughly evaluated. In dynamics category, accuracy in word selection and use, sentences structure, spelling, punctuation, and capitalization were the subjects of attention and assessment. 


\section{Results}

In order to find out whether SIB metacognitive CF plays a significant role in the writing development of the EFL learners, an independent-samples t-test was run to compare the scores obtained from the participants in the first group with those of the second group. Descriptive statistics for the two groups presented in Table 1 indicated that the group receiving SIB metacognitive $\mathrm{CF}$ for the errors had a higher mean in organization $(\mathrm{M}=20.40, \mathrm{SD}=2.61)$, style $(\mathrm{M}=21.12, \mathrm{SD}=1.73)$, and mechanics $(\mathrm{M}=20.84, \mathrm{SD}=2.17)$, while it was in the content category that the second group (i.e., the ones receiving only metacognitive $\mathrm{CF})$ scored a higher mean $(\mathrm{M}=20.50, \mathrm{SD}=2.40)$ than the first group $(\mathrm{M}=19.96, \mathrm{SD}=2.16)$.

Table 1. Descriptive Statistics for the Two Groups' Received Corrective Feedback

\begin{tabular}{lllll}
\hline Categories & Group & N & Mean & SD \\
\hline Content & SIB CF & 25 & 19.96 & 2.16 \\
& CF & 22 & 20.50 & 2.40 \\
Organization & SIB CF & 25 & 20.40 & 2.61 \\
\multirow{3}{*}{ Style } & CF & 22 & 20.13 & 1.88 \\
& SIB CF & 25 & 21.12 & 1.73 \\
Mechanics & CF & 22 & 17.18 & 2.50 \\
& SIB CF & 25 & 20.84 & 2.17 \\
& CF & 22 & 17.86 & 2.18 \\
\hline
\end{tabular}

The results obtained from the t-test run (Table 2) indicated a significant difference between the scores of the first and the second groups in terms of style $t(45)=6.32, p<.000$ and mechanics $t(45)=4.66, p<.000$. However, there was no significant difference between the two groups in terms of content $t(45)=-.809, p<.423$. Nor was any significant difference between the two groups in organization $t(45)=.392, p<.697$.

Table 2. T-Test Results between the First and the Second Groups' Post-test

\begin{tabular}{llllllll}
\hline & & $\mathrm{F}$ & $\mathrm{Sig}$ & $\mathrm{t}$ & $\mathrm{df}$ & Sig. (2-tailed) & Mean Difference \\
\hline Content & Equal variances assumed & .21 & .64 & -.80 & 45 & .423 & -.54 \\
& Equal variances not assumed & & & -.80 & 42.68 & .426 & -.54 \\
\multirow{5}{*}{ Organization } & Equal variances assumed & .95 & .33 & .39 & 45 & .697 & .26 \\
& Equal variances not assumed & & & .40 & 43.41 & .691 & $\mathrm{~s} .26$ \\
\multirow{5}{*}{ Style } & Equal variances assumed & \multirow{2}{*}{3.88} & .05 & 6.32 & 45 & .000 & 3.93 \\
& Equal variances not assumed & & & 6.18 & 36.85 & .000 & 3.93 \\
\multirow{3}{*}{ Mechanics } & Equal variances assumed & .154 & .69 & 4.66 & 45 & .000 & 2.97 \\
& Equal variances not assumed & & & 4.66 & 44.16 & .000 & 2.97 \\
& & & & & & &
\end{tabular}

\section{Discussion}

In this study, the effect of spatial intelligence-based (SIB) metalinguistic corrective feedback (CF) on EFL learners' development in writing was taken into scrutiny. As the results indicated, the mean scores of the writing of the group receiving SIB metalinguistic CF for their linguistic errors were higher in mechanics and style. Although the mean score of the group in organization of writing was also slightly higher than the other, the difference was not as significant as in mechanics and style. Results also indicated the second group had a higher mean score in their content of writing despite receiving only metalinguistic CF for their linguistic errors. Therefore, providing the learners with SIB metalinguistic CF for their writing is less likely to differ from the only metalinguistic CF in the content of writing. Considering the significant difference between the two groups, as indicated, the group receiving 
SIB metalinguistic CF for their linguistic errors outperformed their counterparts in the other group in style and mechanics of writing, while content and organization of their writing did not significantly differ after the treatment.

In fact, the integration of spatial intelligence-based materials, such as the colorful supplies to attract the focus of attention of the learners while giving feedback to their writing, as the results of the study indicated, carries a significant role. Rather than using insipid pen or pencil, teachers giving feedback to writing are required to enrich their corrective feedback via using different colorful supplies such as colored sticky notes, markers, and highlighters to grab the student's attention and sharpen their observation skills. The findings also shed light on the effectiveness of a color-imbedded feedback strategy on the writing performance of the EFL learners. In line with the effectiveness of the spatial intelligence and the integration of visualization, Otto $(2013,48)$ emphasizes that "adding color as a symbolic representation to textual information promotes learners to explore the information in multiple ways, without the limiting parameters of black-and-white text. Color implementation enhance student learning and processing by creating a visual learning plan, giving a map, a routine for students to follow". Looking from a neuroscientific perspective, Zeki (1999) also reported that reading a black and white piece of text does not stimulate the brain regions responsible for processing color, form, and position. Therefore, the associative process cannot be implemented, and this can impede the potential new learning, while activating these parts of the brain with the help of color associations can boost the learning process. As evident, all scholars argue in favor of integrating the color in the process of learning. Hence, this associative mechanism of colors in learning can be benefited from while giving corrective feedback on writing to promote EFL learners' development in writing.

A couple of decades ago, Lange (1983) highlighted the symbolic and suggestive role of color in increasing the perception of information. Many scholars similarly (e.g., Kajs et al., 1998; Keyes, 1993; Leigh, 2010) assert the associative use of colors, believing that it adds an important aspect to the perception of information. To give an example, the color red is generally associated with the word stop possibly because of the traffic signs. Hence, this associative feature of colors as clues can be used in giving feedback to, say, different types of errors. Associating red color, say, with a particular type of grammatical error, or associating a different type of error with a particular color is more likely to lead to recalling the error and relational thinking in new pieces of writing. Otto $(2013$, p. 8$)$ in a similar vein underlines the significance of utilizing "a color-coding approach in combination with research-based writing interventions to distinguish parts of speech and to guide sentence, paragraph, and essay writing" which can pave the way for the learners to more comprehensively realize the process of writing and developing their overall writing skills. He adds that "using different colors eliminates confusion among writing components, structures, divisions, and subdivisions of the writing process" (p. 8). This highlights the significance of color-embedded CF in writing through which the efficiency of CF in general and particularly metalinguistic CF can be promoted.

\section{Conclusion}

Integrating Gardner's theory of multiple intelligences and metalinguistic written corrective feedback on wring of learners, spatial intelligence-based (SIB) metalinguistic written corrective feedback, as the results of the study indicated, is more likely to account for language learner's improvement in writing. The findings shed light to the importance of attention-grabbing techniques in the process of giving feedback to writing. The integration of a color-code scheme with a focus on specific color choices, in relation to writing components and grammatical function, as Otto (2013) asserts, can potentially create awareness among the students toward the structure and organization of the written text, and as it can supply interest to the written text. Hence, the potential effect of a variety of colors in the process of giving corrective feedback to writing would be a fruitful avenue for future studies. Added to that, according to Vyatkina (2011), far fewer CF studies have targeted languages other than English. Hence, the influence of SIB metalinguistic CF on writing in other languages is also an unexplored area that needs to be investigated.

\section{References}

Armstrong, T. (2000). Multiple intelligences. Retrieved May 21, 2015 from $\mathrm{http} / / / \mathrm{www}$.thomasarmstrong.com/multiple- intelligences.htm

Armstrong, T. (2003). Multiple intelligences of reading and writing: Making the words come alive. Alexandria, USA: Association for Supervision and Curriculum Development.

Bitchener, J., \& Knoch, U. (2010). Raising the linguistic accuracy level of advanced L2 writers with written corrective feedback. Journal of Second Language Writing, 19, 207-217. 
https://doi.org/10.1016/j.jslw.2010.10.002

Christison, M. A. (1996). Teaching and learning language through multiple intelligences. TESOL Journal, 6(1), $10-14$.

Ellis, R. (2009). A typology of written corrective feedback types. ELT Journal, 63(2), 97-107. https://doi.org/10.1093/elt/ccn023

Ferris, D. (2006). Does error feedback help student writers? New evidence on short- and long-term effects of written error correction. In K. Hyland and F. Hyland (Eds.), Feedback in Second Language Writing: Contexts and Issues. Cambridge: Cambridge University Press. https://doi.org/10.1017/cbo9781139524742.003

Gardner, H. (1993). Multiple intelligences: The theory in practice. New York, NY, US: Basic Books.

Guenette, D. (2007). Is feedback pedagogically correct? Research design issues in studies of feedback on writing. Journal of Second Language Writing, 16, 40-53. https://doi.org/10.1016/j.jslw.2007.01.001

Heift, T. (2010). Prompting in CALL: A longitudinal study of learner uptake. Modern Language Journal, 94, 198-216. https://doi.org/10.1111/j.1540-4781.2010.01017.x

Hyland, K., \& Hyland F. (2006). Feedback on second language students' writing. Language Teaching, 39, 83-101. https://doi.org/10.1017/S0261444806003399

Kajs, L. T., Alaniz, R., Willman, E., \& Sifuentes, E. (1998). Color-coding keyboard functions to develop kindergartners' computer literacy. Journal of Computing in Childhood Education, 9(2), 107-111.

Keh, C. L. (1990). Feedback in the writing process: a model and methods for implementation. ELT Journal, 44(4), 294-304. https://doi.org/10.1093/elt/44.4.294

Keyes, E. (1993). Typography, color, and information structure. Technical Communication, 40(4), 638-654.

Lalande, J. F. (1982). Reducing composition errors: An experiment. Modern Language Journal, 66(2), 140-9. https://doi.org/10.1111/j.1540-4781.1982.tb06973.x

Lange, B. S. (1983). Toni Morrison's rainbow code. Critique, 24(3), 173-181. https://doi.org/10.1080/00111619.1983.9937784

Lee, I. (1997). ESL learners' performance in error correction in writing. System, 25(4), 465-477. https://doi.org/10.1016/s0346-251x(97)00045-6

Leigh, S. R. (2010). Violent red, ogre green, and delicious white: Expanding meaning potential through media. Language Arts, 87(4), 252-262.

Moody, A. K. (2012). Family connections: Visual supports for promoting social skills in young children: A family perspective. Childhood Education, 88(3), 191-194. https://doi.org/10.1080/00094056.2012.682554

Otto, C. C. (2013). The effects of a color-embedded writing strategy on the written expression skills of students with mild-moderate disabilities (Doctoral dissertation). Retrieved 8 October, 2018 from https://shareok.org/bitstream/handle/11244/19489/Otto_okstate_0664D_13153.pdf?sequence=1\&isAllowed=y

Robb, T., Ross S., \& Shortreed I. (1986). Salience of feedback on error and its effect on EFL writing quality. TESOL Quarterly, 20(1), 83-93. https://doi.org/10.2307/3586390

Truscott, J. (1996). The case against grammar correction in L2 writing classes. Language Learning, 46(2), 327-369. https://doi.org/10.1111/j.1467-1770.1996.tb01238.x

Vyatkina, N. (2011). Writing instruction and policies for written corrective feedback in the basic language sequence, L2 Journal, 3(1), 63-92. https://doi.org/10.5070/12319070

Weigle, S. C. (2014). Considerations for teaching an ESL/EFL writing course. In M. Celce- Murcia, D. Brinton, \& M. A. Snow (Eds.), Teaching English as a second or foreign language (4th Ed.). Boston: Heinle Cengage.

Williams, J. (2005). Teaching writing in second and foreign language classrooms. New York: McGraw-Hill.

Zeki, S. (1999). Inner vision: An exploration of art and the brain. Oxford, England. Oxford University Press. 